\title{
unindra
}

Universitas Indraprasta PGRI

Address: Jl. Nangka No. 58 C (TB. Simatupang), Kel. Tanjung Barat, Kec. Jagakarsa, Jakarta Selatan 12530, Indonesia. +62 (021)

7818718 - 78835283; url: www.unindra.ac.id; cultural.syndrome@unindra.ac.id

\section{Journey of Signs and Shop Signs from Prehistory to Digital Age}

\section{Nanki Nath}

National Institute of Design Ahmedabad

Correspondence regarding this article should be addressed to:

Nanki Nath, nankinath@gmail.com

\section{Article History}

Received : 15-11-2020

Revised : 20-12-2020

Accepted : 24-12-2020

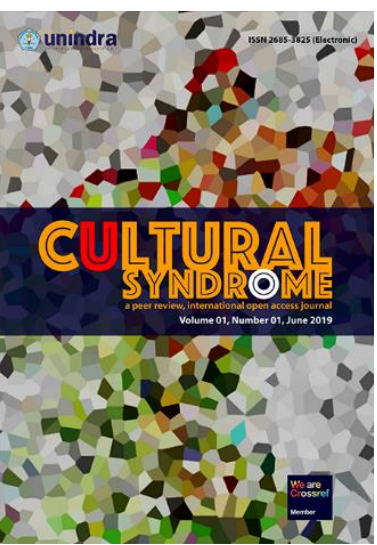

Cultural Syndrome

a peer review, internasional open access journal e-ISSN: 2685-3825

Editor: iD Ahmad Faiz Muntazori

Publication details, including author guidlines https://journal.unindra.ac.id/index.php/cusy/ about/submissions\#authorGuidelines

\section{How to cite this article (MLA 8th)}

Nath, Nanki. "Journey of Signs and Shop Signs from Prehistory to Digital Age." Cultural Syndrome, vol. 2, no. 2, 2020, pp. 99-111, doi: http://dx.doi.org/10.30998/cs.v2i2.517.

The readers can link to article via http://dx.doi.org/10.30998/cs.v2i2.517

\section{SCROLL DOWN TO READ THIS ARTICLE}

Universitas Indraprasta PGRI (as Publisher) makes every effort to ensure the accuracy of all the information (the "Content") contained in the publications. However, we make no representations or warranties whatsoever as to the accuracy, completeness, or suitability for any purpose of the Content. Any opinions and views expressed in this publication are the opinions and views of the authors, and are not the views of or endorsed by Universitas Indraprasta PGRI. The accuracy of the Content should not be relied upon and should be independently verified with primary sources of information.

\section{(c) (i) (5)}

This work is licensed under a Creative Commons Attribution-NonCommercial 4.0 International License.

Copyright by Nanki Nath (2020)

The authors whose names are listed in this manuscript declared that they have NO affiliations with or involvement in any organization or entity with any financial interest (such as honoraria; educational grants; participation in speakers' bureaus; membership, employment, consul tancies, stock ownership, or other equity interest; and expert testimony or patent-licensing arrangements), or non-financial interest (such as personal or professional relationships, affiliations, knowledge or beliefs) in the subject matter or materials discussed in this manuscript. This statement is signed by all the authors to indicate agreement that the all information in this article is true and correct 


\title{
Journey of Signs and Shop Signs from Prehistory to Digital Age
}

\author{
Nanki Nath \\ National Institute of Design Ahmedabad
}

\begin{abstract}
The published research related to history of signs presents a generic commentary. Therefore, this paper presents a detailed scrutiny of the essence and the narrative behind the evolution of signs [focus: shop signs]. According to The Complete Encyclopedia of Signs and Symbols, 'Signs are vehicles for information and meaning, operating on many different levels - the universal and particular, intellectual and emotional, spatial and temporal, spiritual and material.' Later periods of human civilization witnessed a conscious shift from the traditional industry to a knowledge-based economy that inculcates information-digitization. These signs were not only reflections of owners' tastes and personality, but also formed the ethnic makeup of a street market. Gradually in the digital age, commercially oriented signs started giving continuity to public spaces and built streetscapes. This paper brings forth an emergence of signs and shop signs in India, rest of the Asian Pacific Rim countries followed by European countries and finally the Western Pacific Rim countries in North and South America
\end{abstract}

Keywords: Digital Age, History of Shop Signs, Prehistory, Semiotics, Sign Design

Correspondence author: Nanki Nath, nankinath@gmail.com, Ahmedabad, India

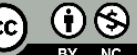

This work is licensed under a CC-BY-NC

\section{Introduction}

Signs are everywhere around us in myriad forms: tangible or intangible and verbal or visual depending on their nature and functions. In old times, a housewife generally bought what she needed at stalls that were regularly set up at smaller scale on local streets and were ultimately dismantled for newer ones to follow. Gradually, stalls got replaced by permanent shops in clusters connected to the living space above or behind as part of small buildings (Figure 1). 


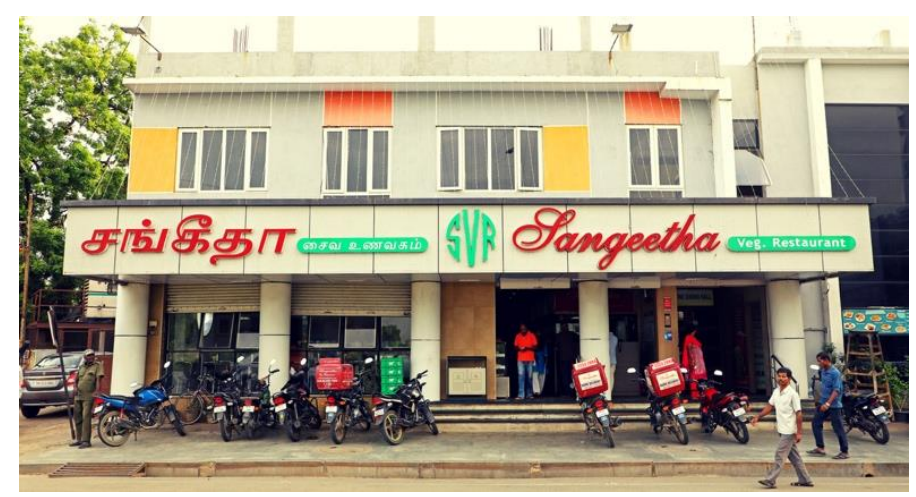

Figure 1 Sangeetha Restaurant, Chennai, India.

Photo courtesy: Aranha

Shops make a significant contribution to the distinguishing character of any street market as well as the outdoor commercial business face at large. In addition, they also represent an important link with the social and cultural history of a place, family business, architecture, so on and so forth. Shop signs may be considered as quintessential urban markers of business and trade in a city. They allow us to unravel the fascinating dimensions of the visual culture of cities that represent diverse expressions, functions and integrations into visual relationships. The structure and order in shop signs is the result of visual design and elements that are used to craft names, tag lines and other content displayed on the panels. Therefore, shop signs include much more than what is seen at first glance. They involve the science of elements, their arrangements, meanings, functions as well as identity creation based on social, cultural, commercial, political and historical criterion. Therefore, in the context of the research study envisaged in the present paper, a 'shop sign' imbibes two very distinct contributions as part of a cityscape as follows: 1) a shop sign is a distinct element of a street culture that fascinates with respect to history, culture and social identity of a marketplace, city and its people. In context of India, there are hardly any textual records that describe this role of shop signs, 2) shop signs can also be considered as genuine urban markers of the various trades and crafts in a city ( $\underline{Y i})$. As artifacts, they also constitute the material culture prevalent in marketplaces of different cities in India.

There are signs in general that existed much before the coming of written records and the beginning of civilization. In those pre-historic times, signs existed as symbols over or in other forms of visual communication mediums such as tablets, seals, caves, rocks, sculptures etc. We could collect different symbolic and other forms of signs during pre-historic times belonging to a few countries in the historical journey of signs and shop signs ahead. Much later, periods of human history and civilization witnessed a conscious shift from the traditional industry to a knowledge-based economy that inculcates information-digitization. It includes signs in form of tangible boards or panels displaying texts that speak of people who run business, shops and firms. They are not only reflections of owners' tastes and personality, but also form the ethnic makeup of a neighborhood or a street market and its character, as well as the social and business activities carried out in forms of old shop fronts or shop houses (Liebs). Gradually, in 
the digital age the commercially oriented signs started giving continuity to public spaces as well as built streetscapes. For instance, landmarks and signposts represent individuality that is not dependent on the property over which they stand or the building façade that carries them at times. Furthermore, in this information-digitization age of uniform franchise signs and generic plastic box signs, the old forms of fronts, houses, guild signs etc. tend to attract by their individuality. They envisage a clever detail, a daring use of color and motion or a reference to particular people, shops or events (Liebs; Phillips). We have included those historical records of signs and shop signs for each country that have been part of published literature. The individual time periods of signs and shop signs are not identical for each of the countries covered. In addition, the following journey does not present a continuous or chronological view of emergence of signs and shop signs in every country. The following section brings forth an emergence of signs and shop signs in India, rest of the Asian Pacific Rim countries followed by European countries and finally the Western Pacific Rim countries in North and South America.

\section{Signs and Shop Signs from The Asian Pacific RIM Countries}

\section{India}

Signs in India, since antiquity, go back to the earliest forms of significations in the Indus valley civilization, 2600-1900 B.C. The rich Indian symbols and forms of beliefs and rituals have gradually developed to the fundamental pre-Vedic folk myths and legends influencing the daily fabric of life in past as well as the present (Damodaran). Since early 19th century till present times in India, age-old technologies co-exist with the high-tech world, bullock carts sharing the roads with fords and shanties being as much part of the cityscape as are the numerous skyscrapers. As a result, a very distinct visual language of signboards has emerged giving streetscapes in India a unique identity. In the context of India, actually both traditional and modern shop signs seem to function more as visual communication exemplars of the vast and rich crafts or some other ephemeral forms of visual culture pervading different marketplaces as a collective unit display of material culture. Illustrated are specimens of hand-painted craftsmanship of two sign-painters who paint boards, hoardings and truck graphics in old Delhi from a project that is dedicated to preserve the typographic practice of street painters in India (Figure 2).

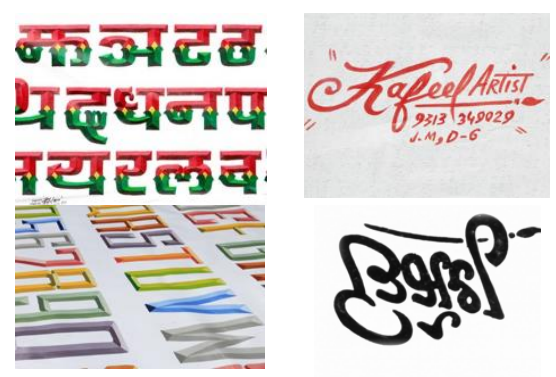

Figure 2 Images from the HandpaintedType.com (2011) by Hanif Kureshi and team, New Delhi 
In addition, there's a historical narrative to understand the evolution of signs as pictorial symbolic depictions to handsome shop fronts/exteriors adorned with signboards (Figure 3), from different time periods; representing different shades of traditions, cultures, movements, genres and styles in signs and signboards of India as follows: 1) Vedic times: The Harappan civilization, 2600 BCE to 1900 BCE, 2) Epic times: Hindu kingdoms on the Ganges, 1400 BCE to 1000 BCE, 3) Rationalistic times: Hindu expansion over all India, $1000 \mathrm{BCE}$ to $320 \mathrm{BCE}$, 4) Buddhist times: ascendency of Magadha, signs from $320 \mathrm{BCE}$ to $400 \mathrm{CE}$, 5) Pre-industrialization times: 15th century to early 19th century, 6) Modern times: 20th century and onwards.
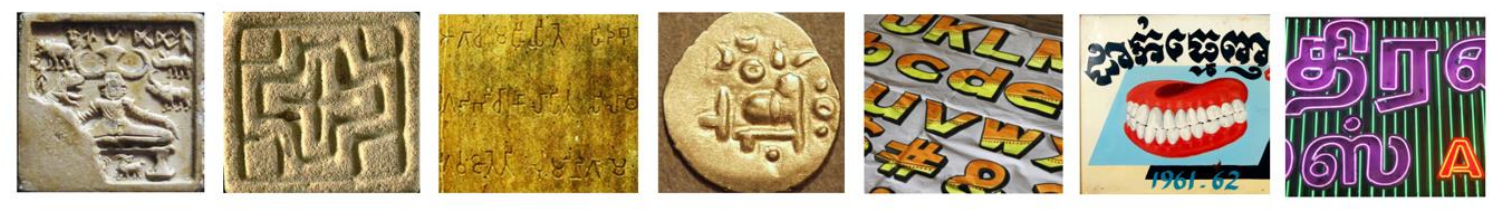

Figure 3 Images from the HandpaintedType.com (2011) by Hanif Kureshi and team, New Delhi

\section{Nepal}

A key theme running across the Nepalese history is the country's status as a cultural contact zone that represents Nepal's great ethnic and linguistic variety (Whelpton). Parbatiyas or 'people of the mountains' culture dominate the Nepalese state. In context of signs and symbolic meanings, Nepal enjoys a great heritage and culture. The Nepalese culture represents a fusion of Indo-Aryan and Tibeto-Mongolian influences. This has been the result of a long history of migration, conquest and trade. Auspicious signs, including the ancient Hindu swastika and Shiva's trident are used to decorate buses, trucks and walls. Unlike India, in Nepal at two main time periods emerged (Figure 4); when the signboards for shops were created by the ancient technique of hand-paint as well as others of the modern times reproduced digitally or in available modern fabrication materials as follows: 1) Age of Renaissance: inscriptions and symbolic forms, 17th century and 18th century, 2) Post-industrialization times: Hand-painted signs, 19th and 20th century onwards.

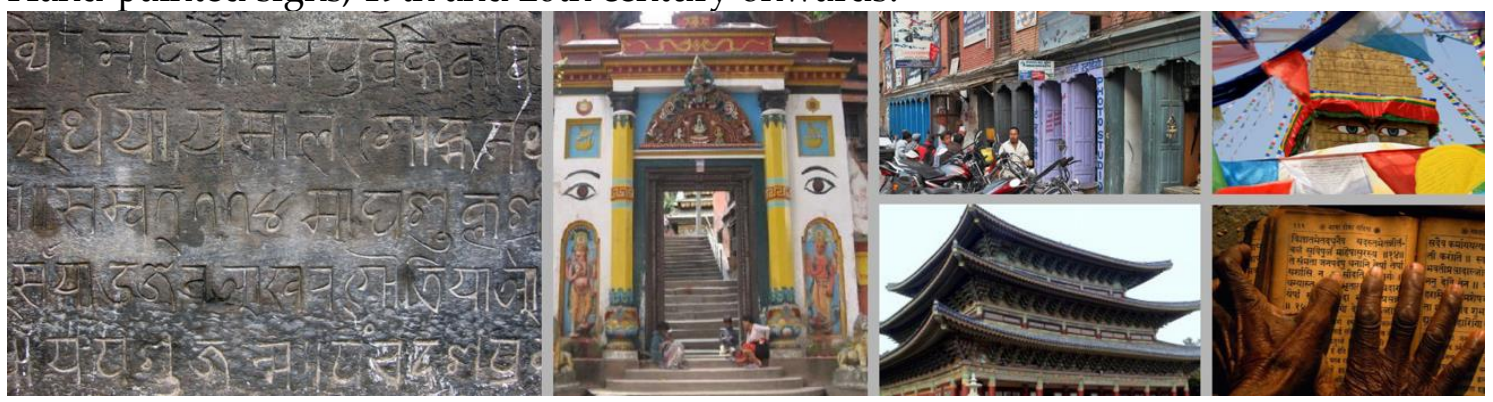

Figure 4 Images Courtesy: http://www.nepalsutra.com/

\section{Malaysia}

In ancient Malaysia, the Malay culture, power structure of state dignitaries and the princes in those times showed influences of more than one religion such as those of Hindu and Buddhist religions. Malaysia has now an ethnic and cultural mix of Malays, 
Chinese and Indians among the locals (De Ledesma et al.). The entry of later Islamic art into the Malaysian visual culture made floral designs and related patterns very popular in those times. Post the 1950s when Malaysia became an independent nation, Malaysian contemporary artists tried to develop their own art and began to avoid the controlling influence of western art that existed during the ancient colonial times. For instance, among the visual artifacts on display in this country have been the Malay manuscripts and writings together with Malay cultural material such as keris, a traditionally crafted Malay weapon ( $\underline{\text { Ayob}})$. The journey of Malaysian signs can be traversed through three periods as follows: 1) Early Development in Signs: 7th-14th century, 2) Malay Vernacular style signs: 14th-18th century includes an interesting case study of ancient shop house designs in a culturally rich and commercially now affluent trade centre of Georgetown in Malaysia (Figure 5), 3) Chinese Baroque style signs: early 19th till late 20th century.

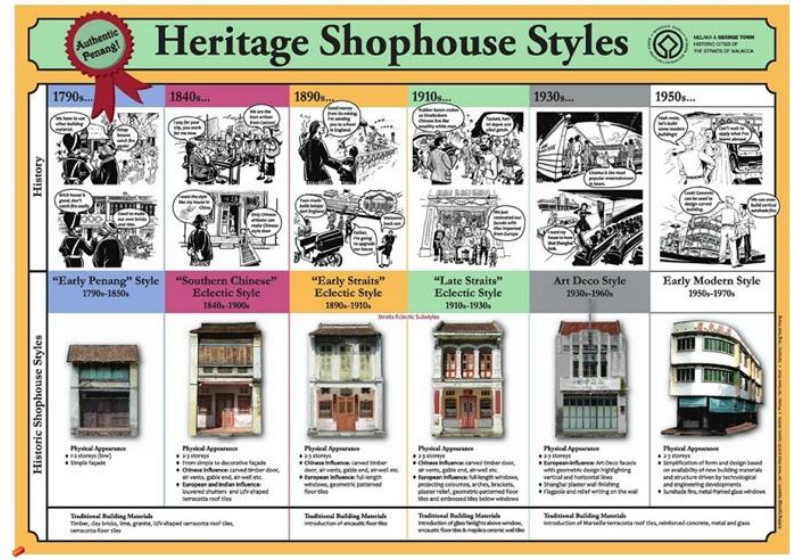

Figure 5 Heritage shop house styles, George Town, Malaysia.

Courtesy: https://penangshophouse.blogspot.in/

\section{Singapore}

Unique is the word that best captures Singapore. The dynamism in colors and richness in sign designs are a harmonious blend of the culture, arts and architecture of the island country. However, Singapore Tourism Board (STB) changed the slogan from 'Unique Singapore' to 'Your Singapore' in 2010 in order to enhance the feeling of belongingness with the dynamic city (Figure 6).

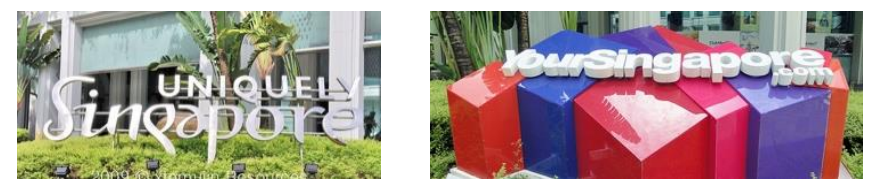

Figure 6 Uniquely Singapore (sign) in 2009 to Your Singapore.com (by STB around 2010).

The historical collection of signs and signage from Singapore do not represent a strict chronology, but depicts milestone styles at different points of time, as follows: 1) Pre-industrialization times: shop houses and store fronts in 19th century, 2) Neo-classical and Art deco styles times: building signs in early 20th century, 3) Post-industrialization times: modern shop houses and signs, 20th and 21st century. 
Cambodia

The available records, as part of published literature of shop signs from Cambodia in particular have been archived in form of published literature celebrating the eternal beauty of hand-painted text, forms and colors in commercial context of business and promotional design. Most of the colorful shop signs, that represent everyday goods and services have been painted on sheets of metal by artists in tiny makeshift studios (Duzaryan). This paper studies signs from the city of Phnom Penh in Cambodia under following genres and chronologies: 1) Classical times: signboards from 1930s till 1950s, 2) Cambodian nationalism times: signs belonging to the dark 1970s, 3) Cinema and romance: Cambodian female actors signs in 1980s, 4) Fashion savvy times: Phnom Penh look in the hand painted signs from 1990s till date (Figure 7).
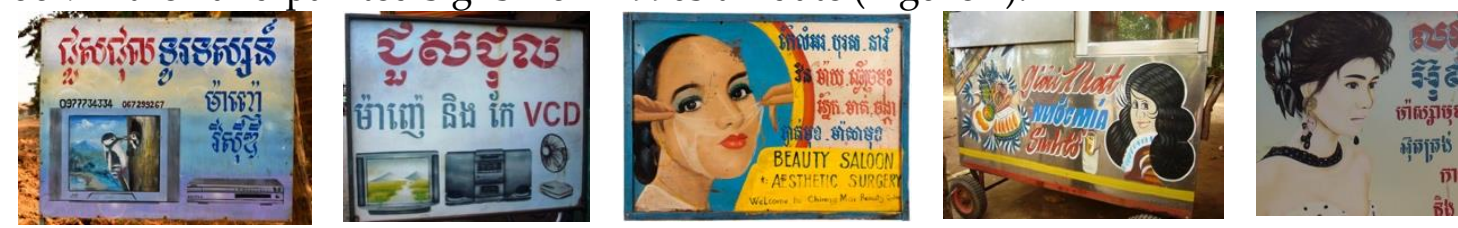

Figure 7 Commercial local shop signs from Phnom Penh, Cambodia (from 1950s - till 2000s)

In addition to above, a detailed collection of shop signs from rest of the Asian Pacific Rim countries: Thailand, Indonesia, Hong Kong, China, Japan; are also part of my doctoral research overview in the thesis (Nath). Summarizing this research, it can be inferred that the majestic nations of Asia are representative of varied forms and styles of signs and shop signs that have evolved under rich influence of ancient abstract forms, iconography, art, entertainment, social events, techno-savvy themes or at times, a devotional reliance on the styles of architectural facades etc. Among the journey described in the south Asian countries of India and Nepal, signs in India have huge influence of various civilizations that pioneered since pre-history. With limited published literature of Nepal signs, we could collect signboard designs for shops based on production techniques of hand-paint and digital art. Moving ahead, among southeastern nations, Malaysia and Singapore signs have influence of city architectural façade design styles in Malay land and color or form related popular styles like Art Deco in case of Singapore. Written forms and art related significations exist in case of Indonesia. Among the eastern Asian group, China and Hong Kong narrate a historical compendium of shop fronts and houses, their related visual and material representational styles at the backdrop of distinct streetscapes.

\section{Signs and Shop Signs in the European Countries}

A subtly applied concept of on-premise advertising gradually emerged in Europe; with definite records of it over stone and on bricks as early as 3000 B.C. After that, some time later a continuum of conventional forms of signage started historically for the first time on massive tall columns in Rome. The earliest medium to advertise messages and business information, however, came quite later via a town crier in built streetscapes of a city. As trade developed, the producer had a fixed location and called attention to the merits of his goods by hanging them outside the shop. During the Middle ages, street 
signs became more advanced and many intersections in European countries had signs pointing the way to cities and towns, sometimes including distances on different kinds of sign panels as well. All this is weaved into a chronological order as part of history that starts from symbolic signs to specific sign kinds and styles, that appear in prominence at different points of time in different countries of Europe.

Many of these expressions/styles are rooted in the archaeology, rather than a devotional reliance on place specific or prominently architecture-specific influences and causes for the emerging faces of signs and later shop signs. Countries like Rome and Greece show the initial symbolic forms, or in other words, tokens of meaning hung outside business shops; followed by other insignia and commercial signage in France, Spain, Sweden, Germany, Italy, Hungary and United Kingdom. The following overview brings forth various sign identifications as symbolic forms and other commercial shop signs with examples at characteristic junctures in the narrative of shop signs journey in European land as follows:

\section{Prehistoric cave art: signs as precursors of writing:}

This era mainly started in the heart of European countries like France and Spain with creation of useless tokens or objects. As speculated by Pre-historians, many such cave art acted as abstract visual signs with large representations of animals as collective or independent clustered units. For instance, we can see the best of examples in FranceLascaux cave paintings and Spain well-known for the Altamira paleolithic cave art, painted as well as engraved cave (Figure 8). Other overviews on Pre-historian Jean Abélanet's wordless signs. Perhaps, most of these wordless drawn messages, as signs are the vestiges of some religious themes tied to rocks, mountains, or the super-abundant water in the high, isolated valleys where they appear in France and Spain. Other speculation by few scholars holds the belief that these figures had an economic function (Figure 9).
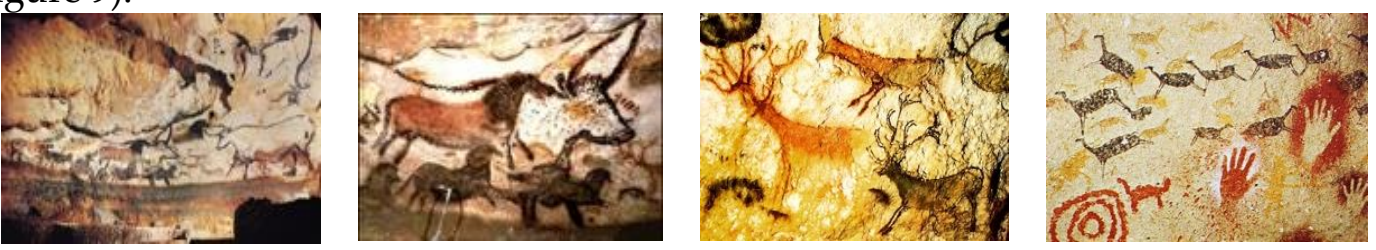

Figure 8 Wall Paintings and Engravings in Lascaux caves, France and Altamira caves in Spain
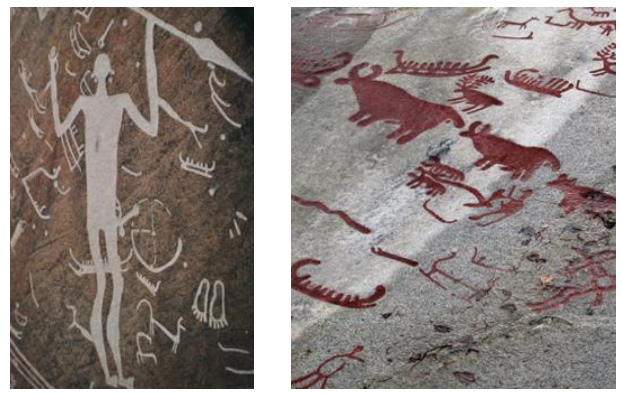

Figure 9 a. Masculine figure rock engraving at Tanum, Sweden (1400 B.C.). George Jean (1989), b. Rock painted grazing animal carvings at Tanum, Sweden. 


\section{Sans Signboard Times in Rome and Greece: 11th till 15th centuries}

The very earliest clear testimonies of sans signboard times can only be deciphered from ancient Roman signs. Of these, very few were painted signs. As per the rule governing signs in those times, the sign panels were made of stone or terracotta. For instance, sign for a dairy was represented by a goat form and a mill by a mule (Figure 10). To grab the attention of the wayfarers in Rome the sign makers applied another smart approach. For instance, a wine-seller accumulated sales of wine for himself by a sign that depicted the evergreen wine bush (Figure 10).
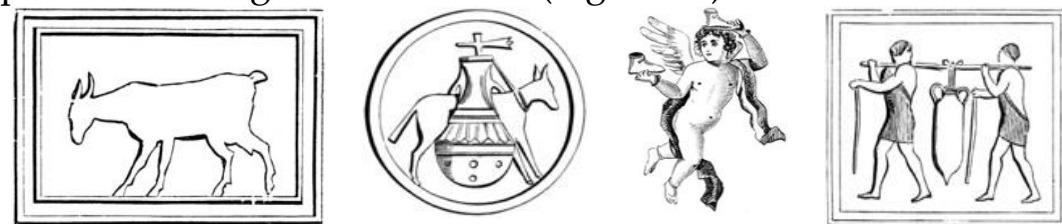

Figure 10 Signs for Dairy, Baker, Shoemaker and Winemerchant (from left to right) in the city of Pompeii, A.D. 70

Greek signs in those times seemed to be very meager and indefinite in occurrence as well as appearance. Signs in Rome used imagery more than text since many people were illiterate during those times. For instance, there were also signs to identify taverns and workshops, generally fabricated in raw materials such as wood, stone or on surface of metallic pottery. For instance, the symbolic Bush as their tavern-sign (Figure 11) gave rise to the famous proverb Good Wine needs no Bush. Religious relief and freestanding sculpture was mostly carved in stone, although wood carving was also common (Figure 12). There were paintings of Gods and a range of artistic tributes to kings and secular rulers were also seen (Figure 12).
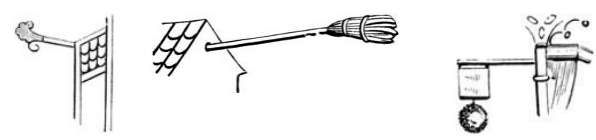

Figure 11 The famous 'Bush' Tavern signs on Roman streets (left to right: ca. $11^{\text {th }}, 14^{\text {th }}$ and $15^{\text {th }}$ )
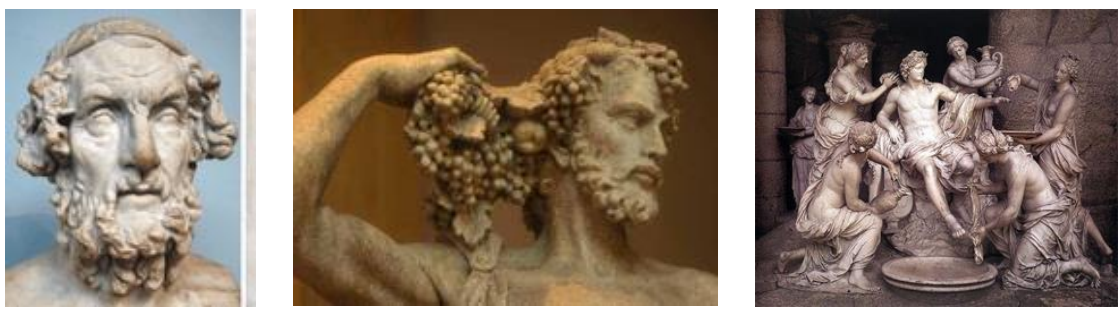

Figure 12 Homer: author of the Iliad and the Odyssey, and Aeolus: in Greek Mythology [left, middle]; Aeolus, ruler of the winds (right)

Writing systems: signs of picture-word combinations, $16^{\text {th }}$ century

Aztec developed 'Codex Boturini', that dates to the time of the Spanish conquest of Mexico in 16th century. In this, small icons are drawn in a linear fashion as ideographic pictures, the visual example being only a rudiment of a phonetic example. The brownish footprints in the image aid reading from bottom to top as well (Figure 13). 


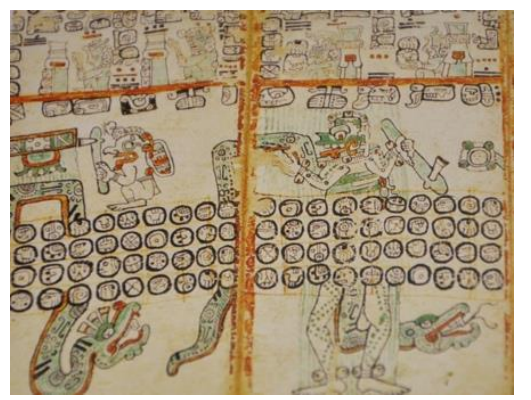

Figure 13 Pages from Maya Madrix codex of picture-words. Book Source: Signs, Symbols and Ciphers by George Jean (1989)

In addition to above, a detailed collection of shop signs from other time periods have been part of the doctoral research; as follows: 4) Town life of Medieval Europe: signs from mid-16th century till 20th century, 5) Shop signs in the Digital age, late 20th century and onwards. In a nutshell, historical records of signs from pre-historic times in Europe to digital age is mutually homogenous than collectively exhaustive and countryspecific separate journeys of signs and shop signs in the Asian land. Influences in these countries too have been from pre-historic cave art and other abstract and symbolic pictorial forms present on rocks, art and sculpture, writing etc. But, more prominently, we see a dominance of the symbolism having a parallel union with material craft such as the signs as guilds, labels, solid hanging fascia etc. We can summarize them as popular forms of signification, for instance, in France and Spain indicate more popular signs in the caves; Rome and Greece envisage popularity of signs in context of religious themes explored by artists and sculptors. While, the other side of London signs are more synonymous with the typical Victorian mood often associated with their unique guild signs, trade signs and ancient shop fronts.

\section{Signs and Shop Signs in the Western Pacific Rim Countries}

A compendium of prominent western pacific rim nations could be included in this journey of respective signs and shops signs; under two categories, as follows: 1) Journey of Shop Signs in North America (includes Canada, USA, Mexico), 2) Journey of Shop Signs in South America (includes Columbia, Brazil, Chile). Taking a little dive into the historical context, if we exclude the European concept as a separate paradigm, our meaning of the 'Western Culture' here has its roots in the Classical period of the GrecoRoman era and the rise of Christianity in the 14th century. Other drivers of Western culture include Latin, Celtic, Germanic and Hellenic ethnic and linguistic groups. In this century especially, the self-identity of Western culture is getting blurred since it can be seen in almost every country in the world (Zimmerman). The other popular social face of the western identity is its Rapand Hip-Hop culture that has majorly governed the people, their likes and dislikes and their lifestyle. In the context, the promotional advertising display designs on signboards have suffered with time with this idea born in the US in 1930s. By 1950s, consumerism came to limelight and reached popularity in the $70 \mathrm{~s}$ and $80 \mathrm{~s}$ with a very sophisticated advertising agency involving big, propagandish signs and pop-art celebrating the theme (Figure 14). 

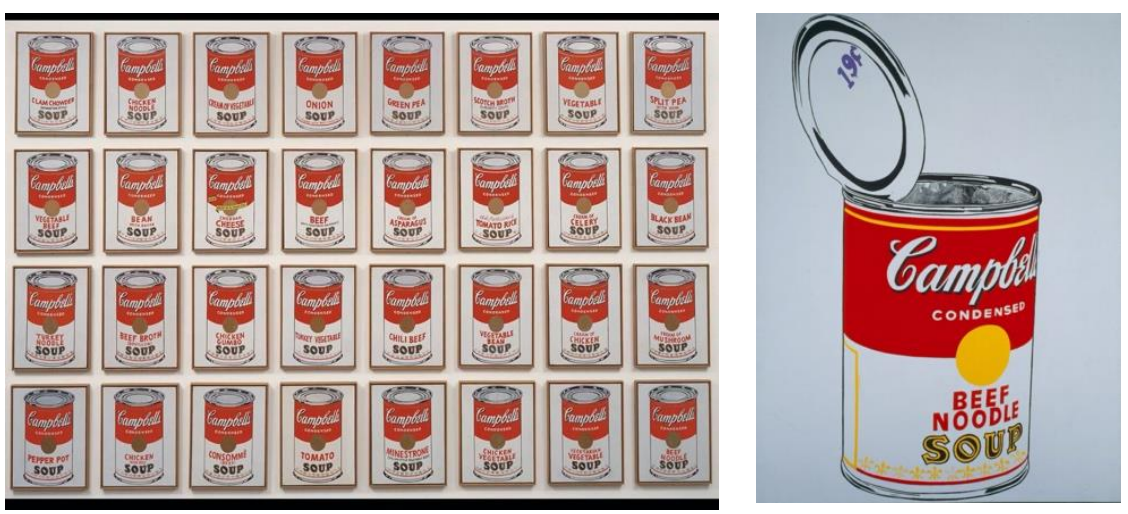

Figure 14 'Campbell soup cans' life-size paintings by Andy Warhol.

Book Source: $\underline{\text { Rubin }}$

The western sign and shop signs journeys took us through the journey of the visual cultural evolution of sign communication in the prominent paradigm of mass production, advertising and a planned obsolescence in the atmosphere to achieve market aims in hyper mobile society of the western countries. In America especially, there was a time in the 1980s, when storefronts, murals, banners, barn signs, billboards, and even street signs were all hand-lettered with brush and paint. But, like many skilled trades, the sign industry has been overrun by the techno-fueled promise of quicker and cheaper. The resulting proliferation of computer-designed, die-cut vinyl lettering and inkjet printers has ushered a creeping sameness into America's visual landscape.

\section{Conclusion}

Archeological layers of evolving meanings in time

This historical journey of signs and shop signs in Asia to Europe to Western lands presents multiple forms of surviving or erstwhile historical signs, along with new additions of more commercial face of signs in digital age of present times. They together are like archeological layers that reveal different periods of human civilizations, their transformations, changing modes of human occupancy and use of spaces through modern versions of signage and wayfinding design.

Since, buildings undergo a change in ownership, the signs too undergo a structural and functional change. For instance, this is particularly present in the signboards and signage of 1920s-30s that included a classical color palette and celebration of the Art Deco and Depression Modern lettering. Likewise, the use of neon in the 1940s and 1950s in few Asian Pacific Rim countries of Hong Kong, Thailand, Korea and Japan and the Western countries of United states and Brazil reflect a causal occurrence of gas-tube technological upsurge that are rooted in the changed architectural fascia/façade vogues/trends. 


\section{Socio-cultural significance of signs and shop signs in time}

On the other side, we can also infer that the socio-cultural significance of signs combined with their transitory nature seems to make the preservation of the pre-historic forms of signs more mysterious and include paradoxes. For instance, few cities such as New York in USA or the neighborhoods of Hong Kong that have retained the old charm of neon technology as a sign craft. However, these efforts are still within the restricted or regulatory bylaws prominently processed to allow visibility of signs and signage in cityscapes. Therefore, if trends of display, laws and business is constantly changing hands, then how the old forms of signs be put to reuse in order to harmoniously convey the texture of daily life from the pre-historic past in the present digital age.

\section{Geography and the matter of meaning making through signs}

Geographically, shop signs seem to be closely intertwined within the history of a city's urban development and other social events. The activity of buying and selling of goods has been a tradition since long time with the first beginnings in Asian countries followed by the European and Western countries. The need to install a visible signboard or structuring a distinct shop front came along with the need to advertise and persuade more and more of trade and business.

Over the years now in these modern days, a signboard is seen as a very unimportant object: it was not always so. Historical analogies are often misleading unless we constantly bear in mind the great difference in details, even when the resemblance in the outline seems most striking (Dutt). Similar is also the case with the journey of signs to more commercial forms of signs for trades and business shops, starting from the pre-history till the modern digital age of signage. The social and economic factors, politics, development of cultures and written inscriptions on buildings and coinage form a common motif that influence the evolution and development of signs and shop signs in the Asian pacific countries and also in the European countries.

The narrative starts with the evolution of signs as seals/symbols/similar emblematic forms in earliest 2600 BC onwards in India. In India, the evolution of signs along with the themes is characteristic of certain eras / centuries that influenced the emergence of different forms of communicating ideas and messages through signs. The different time periods imbibe parallel cultural, local and functional themes. The evolution traced in other Asian as well as European countries brings forth the demographic core of these native countries or their place-specific identities. This comes across as a definite contrast to the traced evolutions in India, wherein the nature of the visual identities and styles emerge from the unique arts and crafts employed in the making of signs.

However, in the western shop sign designs, their evolution shows more prominence of the parameters that make different components of a sign's design and its material representation rather than on the basis of any place specific associations. In these countries, we see that the visual syntax, hierarchy and material identity underwent a range of changes resulting in a clear classification of shop signs and fronts. 


\section{Acknowledgements}

This paper is dedicated to my PhD guide Prof. Ravi Poovaiah, IDC School of Design, IIT Bombay. His undying support and faith in the course of research for my doctoral thesis (2009-2015); has been instrumental for me to work ahead as a researcher in and for design. The present paper highlights an articulation of the introductory chapter from my PhD thesis, "Visual Framework of colour analysis of shop signs in cities of India", IDC School of Design, IIT Bombay, 2005.

\section{References}

"Rock Art from Tanum, Sweden." https://www.johngraycentre.org/about/museumsservice/exhibitions/footprints-in-the-landscape-exhibition/dig-deeper/digdeeper-rock-art-and-symbol-stones/.

Aranha, Jovita. "Sangeeta Restaurant." The Better India. https://enmedia.thebetterindia.com/uploads/2018/07/How-a-Small-Udupi-Eatery-Startedby-a-School-Dropout-Became-a-300-Cr-Food-Chain1.jpg? $\mathrm{dpr}=1.0 \& \mathrm{q}=70 \&$ compress $=$ true $\&$ quality $=90 \& \mathrm{w}=1080$.

Ayob, Salwa Hj. "Colonialism and Visual Culture: A Study of the Effect of Colonialism on Visual Culture with Particular Reference to Malaya (Malaysia)." University of Wales Institute of Cardiff.

Damodaran, Kizhedath. Indian Thought: A Critical Survey. Asia Publishing House, 1967.

De Ledesma, Charles et al. The Rough Guide to Malaysia, Singapore E Brunei. Rough Guides UK, 2012.

Dutt, Romesh Chunder. Epochs of Indian History: Ancient India. edited by John Adam, Longmans Green and Company, 1904.

Duzaryan, S. "Signs of the Times in Cambodia." http://newsroom.ucla.edu/stories/signsof-the-times-in-cambodia-241447.

Jean, Georges. Signs, Symbols and Ciphers: Decoding the Message. Thames and Hudson, 1998.

Liebs, Chester. Main Street to Miracle Mile: American Roadside Architecture. Boston: Little, Brown and Company/ New York Graphics Society, 1985.

Nath, Nanki. "Visual Framework of Colour Analysis of Shop Signs in Cities of India." vol. Master, Thesis, Indian Institute of Technology Bombay, 2015. 
Phillips, Peter H. Sign Controls for Historic Signs", Pas Memo. American Planning Association, 1988.

Rubin, Susan Goldman. Andy Warhol: Pop Art Painter. Abrams Books, 2006.

Whelpton, John. A History of Nepal. Cambridge University Press, 2005.

Yi, Feng. "Shop Signs and Visual Culture in Republican Beijing." European Journal of East Asian Studies, vol. 6, no. 1, 2007, pp. 103-128, doi:https://doi.org/10.1163/157006107X197682.

Zimmerman, Kim Ann. "What Is Culture?" July 13 https://www.livescience.com/21478what-is-culture-definition-of-culture.html. 